\title{
Dietary diversity, meal frequency and associated factors among infant and young children in Northwest Ethiopia: a cross- sectional study
}

\author{
Melkamu Beyene ${ }^{1}$, Abebaw Gebeyehu Worku² and Molla Mesele Wassie ${ }^{3^{*}}$
}

\begin{abstract}
Background: Inappropriate feeding practice increases risk of under nutrition, illness, and mortality amongst children less than 2 years of age. The objective of this study is to assess minimum dietary diversity, meal frequency and its associated factors among infant and young children aged 6-23 months in Dangila Town, Northwest Ethiopia.

Methods: A community based cross sectional study was conducted. Simple random sampling technique was used to select study participants. Interviewer administered questionnaire were used. Bivariate and multivariable logistic regression analyses was employed to identify factors associated with minimum dietary diversity and meal frequency.

Results: A total of 920 children 6-23 months were included. Proportion of children who met the minimum dietary diversity and meal frequency was 12.6 and $50.4 \%$, respectively. Mothers education [AOR $=2.52]$, age of a child [AOR $=2.05]$, birth order of index child [AOR $=2.08]$, living in urban area $[A O R=2.09]$, having home gardening $[A O R=2.03]$, and media exposure $[A O R=2.74]$ were positively associated with dietary diversity. Moreover, age of the child [AOR $=3.03]$, birth order of index child [AOR $=1.58]$, mothers involvement in decision making [AOR $=1.51]$, media exposure $[A O R=2.62]$, and having postnatal visit $[A O R=2.30]$ were positively associated with meal frequency.

Conclusion: The proportion of children who received minimum dietary diversity and meal frequency was low. Being at younger age, first birth order, and lack of media exposure affect both dietary diversity and meal frequency. Increasing mother's education, home gardening, mass media promotion and empowering women in decision making are highly recommended to increase dietary diversity and meal frequency.
\end{abstract}

Keywords: Dietary diversity, Meal Frequency, Infant and young child, Ethiopia

\section{Background}

Proper infant and young child feeding practice is needed in the first two years of life for optimal child growth, better health, and development. Complementary feeding practice is a process of starting other foods besides breast milk to meet the increasing demand in terms of nutritional requirement [1-3].

According to the World Health Organization (WHO), indicators of proper complimentary feeding are starting of solid, semi-solid or soft foods, minimum meal frequency, minimum dietary diversity, minimum acceptable

\footnotetext{
* Correspondence: molmesele@gmail.com

${ }^{3}$ Department of Human Nutrition, Institute of Public Health, University of

Gondar, P.O. Box 196, Gondar, Ethiopia

Full list of author information is available at the end of the article
}

diet, and consumption of iron-rich or iron-fortified foods [4].

Inappropriate complementary feeding practices increase the risk of under nutrition, illness, and mortality in infants and young children less than 2 years of age [5, 6]. Greater than two-thirds of malnutrition related child deaths are associated with inappropriate feeding practices during the first two years of life in such a way that infants and young children received inadequately nutritious diets, poorly diversified and infrequently feeding [7]. Malnourished children who survive are also getting more frequently sick and suffer from life-long consequences of malnutrition in their life and perhaps the effect will span generation [6,7].

In Ethiopia, $40 \%$ of children are stunted, $9 \%$ are wasted, and $25 \%$ are underweight which informed the occurrence of both acute and chronic under nutrition. 
Only $4 \%$ of children have been fed using minimum acceptable diet [8]. Detailed analysis of EDHS 2011 showed that 10.8 and $44.7 \%$ of children aged 6-23 months have received minimum dietary diversity and minimum meal frequency, respectively in Ethiopia [9].

Hence the prevalence of malnutrition is still high among the children in Ethiopia and malnutrition is highly associated with low complementary feeding practices (dietary diversity and meal frequency), it is imperative that further research is essential to find out actual feeding practices and factors associated with dietary diversity and meal frequency among Infant and young children.

\section{Methods}

\section{Study design, area and period}

A community based cross-sectional study was conducted to assess the prevalence of minimum dietary diversity and meal frequency among infant and young children aged 6 to 23 months. This study was conducted at Dangila town from March 1-30, 2014. Dangila is located at a distance of $476 \mathrm{~km}$ from Addis Ababa (capital city of Ethiopia) in the Northwest direction.

\section{Source population and sampling}

The source population was all infant and young children 6-23 months old who lived in Dangila. For sample size calculation we used single population proportion formula considering the following assumptions: $95 \%$ confidence level, Proportion (P) of $10.8 \%$ for minimum dietary diversity and $44.7 \%$ for minimum meal frequency and margin of error of $2 \%$ for minimum dietary diversity (rare event) and $5 \%$ for minimum meal frequency. $\mathrm{N}_{1}$ for minimum diet diversity and $\mathrm{N}_{2}$ for minimum meal frequency: $-\mathrm{n}_{1}=(1.96)^{2 *}(0.108) *(1-0.108) /$ $(0.02)^{2}=925$ and $\mathrm{n}_{2}=(1.96)^{2 * *}(0.447)^{*}(1-0.447) /(0.05)^{2}=$ 380. However, for having larger power, we have taken $\mathrm{n}=925$ for our final sample size. . Lists of infants and young children aged between 6 and 23 months along with their mothers residing in all kebeles (the smallest administrative unit) of Dangila Town were taken from health extension workers and then sampling frame was constructed for each kebeles. Simple random sampling technique was used to select a sample of 925 children proportionally from all kebeles by using lottery method.

\section{Data collection procedures}

Data were collected using interviewer- administered and structured questionnaire. The data collection tool regarding the various factors was adopted from EDHS 2011 questionnaire with some modification to fit with the context Moreover, data on dietary diversity and meal frequency were adopted from WHO standardized questionnaire for IYCF practices. This was based on the mother's recall of foods given to her child in the past twenty four hours $(24 \mathrm{~h})$ before the survey.

Household wealth was constructed using principal components analysis to determine the weights for the wealth based on information collected about several household assets and facilities. This wealth index was divided into three categories as poor, middle and rich and each household was assigned to one of these categories.

\section{Operational definitions \\ Minimum dietary diversity}

Proportion of children with 6-23 months of age who received foods from four or more food groups of the seven food groups. The seven foods groups used for tabulation of this indicator were: grains, roots and tubers; legumes and nuts; dairy products (milk, yogurt); Flesh foods (meat, fish, poultry and liver/organ meats); eggs; vitamin A-rich fruits and vegetables; and other fruits and vegetables. Consumption of any amount and quality of food from each food group was sufficient to 'count', i.e., there was no minimum quantity, except if an item was only used as a condiment [4].

\section{Minimum meal frequency}

Proportion of breastfed and nonbreastfed children aged 6-23 months who received solid, semisolid, or soft foods (but also including milk for non-breastfed children). The Minimum frequency was defined as: twice for breastfed infants 6-8 months, three times for breastfed children 9-23 months, and four times for non-breastfed children 6-23 months [4].

\section{Satisfactory exposure to media}

Women aged 15-49 years at least once a week read a newspaper or magazine or listen to radio, or watched television.

\section{Data processing and analysis}

Data were entered and cleaned using EPI-info version 3.5.3 statistical software and then exported to SPSS version 20.0 statistical software for analysis. Dietary diversity and meal frequency variables were dichotomized as category 0 for not meeting the minimum criteria and otherwise taken as category 1 . Descriptive statistics were done. Bivariate logistic regression analysis was used to assess the association between each independent variable with the dependent variables. Those variables that have been associated with the dependent variables at p-value of less than 0.2 were fitted in to multivariate logistic regression models to control the effects of confounding. Those variables having p- value of less than 0.05 was considered as significant. 


\section{Ethical considerations}

Ethical clearance was obtained from the Ethical Review Board of the Institute of Public Health of university of Gondar. Verbal consent was obtained from the participant's mother after informing them all the purpose, benefit, risk, the confidentiality of the information and the voluntary nature of participation in the study. Participants found to have mal practices regarding their infant or young child feeding had been counseled after the completion of the interview.

\section{Results and discussion}

\section{Characteristics of the sample}

A total of 920 infants and young children aged 6 to 23 months along with their mothers were enrolled in the study, with a response rate of $99.5 \%$. For all parental characteristics see Table 1 . Table 2 presents the distribution of the sample according to attributes of the child, household, community and health care characteristics. Among the children, $338(36.7 \%)$ were in the age category of 6-11 months The mean age of children was $14.21 \pm 5.27$ (SD) months, and $90 \%$ of children were breast fed at a time of data collection.

\section{Practices of dietary diversity and meal frequency}

Table 3 indicates the types of food groups practiced by study subjects. Grains, roots and tubers were eaten by $80.2 \%$ of children. The present study found that only $12.6 \%$ of children received the recommended dietary diversity, which is lower as compared with the DHS reports of developing countries from Africa, Asia, and Latin America [10]. This low dietary diversity coverage is also similar with different studies conducted in Ethiopia (10.8 \%) [9], Democratic Republic of Congo (12\%), Burkina Faso (14\%), Mali (16\%), and India $(15.2 \%)[10,11]$. However, it is lower than findings from Nepal (34 \%), East New Delhi (33 \%), Bangladesh (41.9\%), Nepal (72\%), and Sri Lanka (71 \%) [12, 13, 15-17] (Fig. 1).

The difference could be due to lack of awareness about nutritional requirements for infants and young children, affordability to a food product and low purchasing power for food. This population has also different feeding habit with a tradition of cooking few verities of food for the family. Moreover, there appears to be a tendency to share food with siblings at home.

Proportion of children who received minimum meal frequency found to be $50.4 \%$. The practice is higher as compared to EDHS report (44.7\%) [9], Mali (25\%), Burkina Faso (31\%), Democratic Republic of Congo (30\%), Cameron (41\%) and India (42\%) [10, 11]. It is similar with studies conducted in New Delhi (49\%), Vietnam (48 \%), Namibia (49\%) [10, 17]. But it is lower when compared with studies from Asia and Latin
Table 1 Parental level characteristics of children aged 06-23 months, Dangila, Northwest Ethiopia, 2014. ( $n=920)$

\begin{tabular}{|c|c|c|}
\hline Characteristic & Frequency(n) & Percentage (\%) \\
\hline \multicolumn{3}{|l|}{ Parental characteristics } \\
\hline \multicolumn{3}{|l|}{ Mother's age (years) } \\
\hline $15-24$ & 223 & 24.2 \\
\hline $25-34$ & 512 & 55.7 \\
\hline $35-49$ & 185 & 20.1 \\
\hline \multicolumn{3}{|l|}{ Mother's religion } \\
\hline Orthodox & 758 & 82.4 \\
\hline Others $^{a}$ & 162 & 17.6 \\
\hline \multicolumn{3}{|l|}{ Mother's ethnicity } \\
\hline Amhara & 904 & 98.3 \\
\hline Others $^{b}$ & 16 & 1.7 \\
\hline \multicolumn{3}{|l|}{ Marital status } \\
\hline Currently married & 827 & 89.9 \\
\hline Formerly married/not ${ }^{c}$ & 93 & 10.1 \\
\hline \multicolumn{3}{|l|}{ Mother's education } \\
\hline Cannot write and read & 392 & 42.6 \\
\hline Primary education (1-8) & 223 & 24.2 \\
\hline Secondary education (9-12) & 219 & 23.9 \\
\hline Higher education $^{d}$ & 86 & 9.3 \\
\hline \multicolumn{3}{|l|}{ Father's education $(n=848)$} \\
\hline Cannot write and read & 252 & 29.7 \\
\hline Primary education (1-8) & 222 & 26.2 \\
\hline Secondary education (9-12) & 244 & 28.8 \\
\hline Higher education ${ }^{d}$ & 130 & 15.3 \\
\hline \multicolumn{3}{|l|}{ Mother's work } \\
\hline Currently not work & 695 & 75.5 \\
\hline Currently working & 225 & 24.5 \\
\hline \multicolumn{3}{|l|}{ Father's work $(n=848)$} \\
\hline Farmer & 355 & 41.9 \\
\hline Merchant & 149 & 17.6 \\
\hline Government employee & 197 & 23.2 \\
\hline Non government employee & 17 & 2 \\
\hline Self employee & 74 & 8.7 \\
\hline Labor work & 56 & 6.6 \\
\hline
\end{tabular}

${ }^{\mathrm{a}}$ Muslim/protestant/catholic, ${ }^{\mathrm{b}}$ Oromo/Tigre, ${ }^{\mathrm{c}}$ single/divorced/died ${ }^{d}$ college/university, ehousewife/student

American countries like Nepal (82 \%), Kathmandu (65\%), Bangladesh (81\%), Sri Lanka (88\%), and Peru (78 \%) $[10,12,13,15,16]$.

As we see the meal frequency practice is higher compared with same African countries this might be due to difference in feeding habits and had better production and purchasing power compared with others relatively. But much lower than Asian countries, this difference might be due to educational level, habit of feeding 
Table 2 Child, household, community and health care level characteristics of children aged 6-23 months, Dangila,

Northwest Ethiopia, 2014

\begin{tabular}{|c|c|c|c|c|c|}
\hline & & & & & \\
\hline Characteristics & Frequency (n) & Percentage (\%) & No information & 82 & 8.9 \\
\hline Child characteristics & & & Community characteristics & & \\
\hline Age of child in months & & & Residence & & \\
\hline $06-11$ & 338 & 36.7 & Rural & 520 & 56.5 \\
\hline $12-17$ & 287 & 31.2 & Urban & 400 & 43.5 \\
\hline $18-23$ & 295 & 32.1 & Home gardening & & \\
\hline Sex of a child & & & No & 825 & 89.7 \\
\hline Male & 436 & 47.4 & Yes & 95 & 10.3 \\
\hline Female & 484 & 52.6 & Uses of home gardening $(n=95)$ & & \\
\hline Birth order of index child & & & Only for sell & 18 & 18.9 \\
\hline First & 259 & 28.2 & Only for household consumption & 49 & 51.6 \\
\hline Second to fourth & 553 & 60.1 & Both for cell and household & 28 & 29.5 \\
\hline Above fourth & 108 & 11.7 & Health care characteristics & & \\
\hline Currently breast feed & & & Antenatal clinic visits & & \\
\hline No & 100 & 10.9 & Missing & 142 & 15.4 \\
\hline Yes & 820 & 89.1 & $1-3$ times & 156 & 17 \\
\hline Diarrhea for the last two weeks & & & Four and above times & 622 & 67.6 \\
\hline No & 798 & 86.7 & Place of delivery & & \\
\hline Yes & 122 & 13.3 & Home & 229 & 24.9 \\
\hline ARI for the last two weeks & & & Institution & 691 & 75.1 \\
\hline No & 814 & 88.5 & Timing of post-natal check-up & & \\
\hline Yes & 106 & 11.5 & Missing & 295 & 32.1 \\
\hline Household characteristics & & & Within 1-2 days & 81 & 8.8 \\
\hline No of $<5$ children & & & Within 3-6 days & 161 & 17.5 \\
\hline One & 622 & 67.6 & After 7 days & 383 & 41.6 \\
\hline
\end{tabular}

31.4

Three and above

Decision making at household

Mothers not involved

Mothers involved

Exposure to media

Unsatisfactory

Satisfactory

Household Wealth

Poor

Middle

Rich

Sources of information on IYCF

Health professionals 703

Relatives

Friends

Family

Media promotion (radio/television)
Table 2 Child, household, community and health care level characteristics of children aged 6-23 months, Dangila, Northwest Ethiopia, 2014 (Continued)

frequency, lack of knowledge about how many time solid, semisolid and soft food should be given for a child and even if had knowledge lack of affordability to enough food production and purchasing power.

\section{Factors affecting dietary diversity}

The educational status of a mother, age of a child, birth order of index child, area of residence, home gardening and satisfactory media exposure of a mother were significantly associated with providing the minimum dietary diversity after controlling for other predictors in the model (Table 4).

The study found that children born from mothers who were well educated and had a secondary level education [AOR 2.52; $95 \%$ CI $(1.28,4.93)]$ or higher education [AOR 4.23; $95 \%$ CI $(1.92,9.33)]$ had greater odds of feeding diversified foods. A recent study done on comparison of five Asian countries on infant feeding reports that mother's education is a significant determinant of appropriate diversified infant feeding $[18,19]$. Sri Lanka 
Table 3 Types of food groups practiced among 6-23 months children in Dangila, Northwest Ethiopia, 2014

\begin{tabular}{llc}
\hline Food groups & Frequency(n) & aPercentage (\%) \\
\hline 1. Grains, roots and tubers & 738 & 80.2 \\
2. Legumes and nuts & 544 & 59.1 \\
3. Dairy products & 452 & 49.1 \\
4. Flesh food & 22 & 2.4 \\
5. Eggs & 108 & 11.7 \\
6. Vitamin A rich fruits and vegetables & 131 & 14.2 \\
7. Other fruits and vegetables & 68 & 7.4 \\
\hline
\end{tabular}

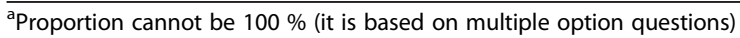

had the highest proportion of children meeting the infant feeding guidelines for diversity; and this is linked to the higher education status of mothers and overall literacy [12]. Similar positive impact of education on diverse feeding practices is also reported in a previous studies in Nepal, Bangladesh, Indonesia, India including Ethiopia $[9,19]$. This could be educated mothers are more likely to have information (media exposure), understand the education message, more likely to be engaged in the paid work and might have received lessons on child feeding in the curricula at school.

Another most important factor significantly associated with minimum dietary diversity was age of a child. Children aged 12-17 and 18-23 months had about two times higher odds [(AOR 2.05; $95 \%$ CI (1.17-3.58) and (AOR $2.89 ; 95 \%$ CI $(1.69,4.93)]$ of having minimum dietary diversity compared to children aged 6-11 months. This study is in line with studies conducted in Ethiopia, Indonesia, Nepal, and Sri Lanka $[9,12,15,19]$. This indicated the relationship between different food groups by age group which implies that food groups decrease as the child age decreases. This might be due to late

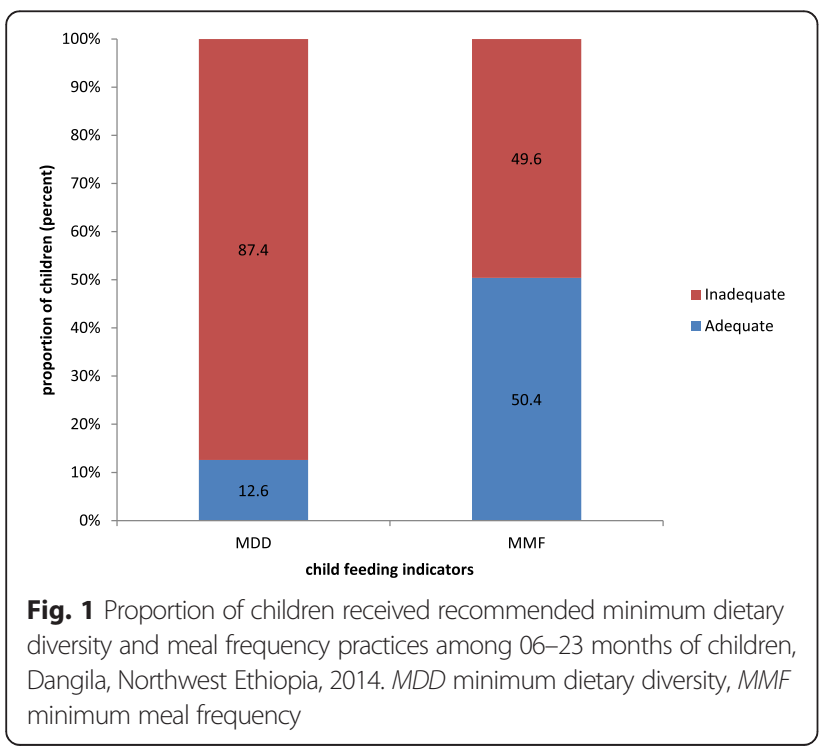

introduction of complimentary feeding and when they start complimentary feeding on time; they included only milk or cereal products like gruel. Other possibility could be mothers may perceive that younger the child, the poor ability of child's intestine to digest solid, semisolid and soft foods. Besides, mothers may assume introducing a bulk of food would lead them to develop infections [20].

It was found that birth order of index child had significant association with dietary diversity. Children born in the second to fourth order [AOR 2.08; $95 \%$ CI (1.24, 3.49)] and above fourth order [AOR 2.76; $95 \%$ CI (1.26, 6.05)], respectively, had about two and three times higher odds of having the minimum dietary diversity compared with children who were born in first order. This result is contradictory to that of previous studies conducted on 2011 EDHS analysis [9]. This difference might be due to study area, sample size and time horizon. This study is conducted in more or less homogenous community with limited sample size; but the EDHS study included large population from different ethnic and regions with various culture, beliefs, and traditions such as a tendency to prioritizing the first child from his/her younger siblings. Another possible reason for this difference may be that as a mother's parity increase, she gets experience on how to prepare and feed diversified diet to her child.

This study also indicated that children born from mothers who lived in urban areas were reported higher practice of minimum dietary diversity [AOR 2.09; $95 \%$ CI $(1.12,3.93)]$ as compared to those children born from mothers who lived in rural areas. This is similar to study conducted in Indonesia [21]. The low practice of diet diversity in rural region may be due to lake of awareness regarding importance of dietary diversity in rural community compared to urban community, which has access to mass media. Another difference may be traditional beliefs and practices. During introducing complimentary food to infants in rural community, infants may develop diarrhea due to poor hygienic condition, but mothers could associate this problem with taking different food items and eventually she might not permit the child to taste unfamiliar foods. Those children with parents possessing home gardening had two times [AOR 2.03; $95 \%$ CI (1.09-3.78)] higher odds of having the minimum dietary diversity as compared to children whose parents did not. This could indicate that parents with home gardening would grow vegetables and fruits and then they child would get additional options in his/her diet. This finding is supported by a study conducted in Southern Ethiopia [22].

Children whose mothers who had been exposed to media had a higher odds of having diversified diet [AOR 2.74; $95 \%$ CI $(1.52,4.94)]$ than those children of mothers who had not been exposed to media. This is 
Table 4 A bivariate and multivariate logistic regression output showing factors associated with minimum dietary diversity practice among 06 to 23 months children, Dangila, Northwest Ethiopia, 2014

\begin{tabular}{|c|c|c|c|c|}
\hline \multirow[b]{2}{*}{ Characteristics } & \multicolumn{3}{|c|}{ Minimum dietary diversity } & \multirow[b]{2}{*}{ AOR $(95 \% \mathrm{Cl})$} \\
\hline & Inadequate & Adequate & COR $(95 \% \mathrm{Cl})$ & \\
\hline \multicolumn{5}{|l|}{ Mother's education } \\
\hline Cannot write and read & $359(91.60)$ & $33(8.40)$ & 1.00 & 1.00 \\
\hline Primary education (1-8) & $199(89.20)$ & $24(10.80)$ & $1.312(0.754,2.282)$ & $1.539(0.831,2.852)$ \\
\hline Secondary education (9-12) & $182(83.10)$ & $37(16.90)$ & $2.212(1.339,3.654)$ & $2.516(1.284,4.929)$ \\
\hline Higher education & $64(74.40)$ & $22(25.60)$ & $3.740(2.049,6.824)$ & $4.230(1.918,9.332)$ \\
\hline \multicolumn{5}{|l|}{ Mother's work } \\
\hline Currently not working & $616(88.60)$ & $79(11.40)$ & 1.00 & 1.00 \\
\hline Currently working & $188(83.60)$ & $37(16.40)$ & $1.535(1.005,2.343)$ & $1.028(0.618,1.712)$ \\
\hline \multicolumn{5}{|l|}{ Age of a child(months) } \\
\hline $06-11$ & $315(93.20$ & $23(6.80)$ & 1.00 & 1.00 \\
\hline $12-17$ & $248(86.40)$ & $39(13.60)$ & $2.154(1.253,3.701)$ & $2.047(1.172,3.575)$ \\
\hline $18-23$ & $241(81.70)$ & $54(18.30)$ & $3.069(1.832,5.141)$ & $2.889(1.693,4.931)$ \\
\hline \multicolumn{5}{|l|}{ Order of index child } \\
\hline First & $233(90.00)$ & $26(10.00)$ & 1.00 & 1.00 \\
\hline Second to fourth & $479(86.6)$ & $74(13.4)$ & $1.384(0.862,2.223)$ & $2.077(1.235,3.494)$ \\
\hline Above fourth & $92(85.20)$ & $16(14.80)$ & $1.559(0.799,3.039)$ & $2.758(1.258,6.046)$ \\
\hline \multicolumn{5}{|l|}{ ARI status } \\
\hline No & $706(86.3)$ & $108(13.7)$ & 1.00 & 1.00 \\
\hline Yes & $98(92.5)$ & $8(7.5)$ & $0.534(0.252,1.128)$ & $0.571(0.264,1.235)$ \\
\hline \multicolumn{5}{|l|}{ Residence } \\
\hline Rural & $448(86.20)$ & $72(13.80)$ & 1.00 & 1.00 \\
\hline Urban & $356(89.00)$ & $44(21.00)$ & $0.769(0.515,1.147)$ & $2.094(1.117,3.926)$ \\
\hline \multicolumn{5}{|l|}{ Home gardening } \\
\hline No & $728(88.20)$ & $97(11.80)$ & 1.00 & 1.00 \\
\hline Yes & $76(80.00)$ & $19(20.00)$ & $1.876(1.087,3.238)$ & $2.031(1.093,3.775)$ \\
\hline \multicolumn{5}{|l|}{ Decision making at household } \\
\hline Mothers not involved & $190(92.20)$ & $16(7.80)$ & 1.00 & 1.00 \\
\hline Mothers involved & $614(86.00)$ & $100(14.00)$ & $1.934(1.113,3.360)$ & $0.913(0.482,1.731)$ \\
\hline \multicolumn{5}{|l|}{ Media exposure } \\
\hline Unsatisfactory & $521(91.90)$ & $46(8.10)$ & 1.00 & 1.00 \\
\hline Satisfactory & $283(80.20)$ & $70(19.80)$ & $2.802(1.879,4.176)$ & $2.738(1.517,4.943)$ \\
\hline
\end{tabular}

similar studies shown in Ethiopia, India, and Sri Lanka $[9,11,12]$. This might be pointing to the influence of the media on infant and young child feeding practices. This could have happened due to the promotions of child nutrition related media advertisement in national radio and television.

\section{Factors affecting minimum meal frequency practice}

Age of a child, birth order of an index child, involvement of mother in decision making in the household, satisfactory media exposure of a mother and time of postnatal care visit were significantly associated with the recommended minimum meal frequency after controlling for other predictors in the model (Table 5).

The study showed that children with age group of $12-$ 17 months [AOR 3.03; $95 \%$ CI $(2.14,4.27)$ ] and $18-23$ months [AOR 5.03; $95 \%$ CI $(3.52,7.18)$ ] had higher odds of recieving the minimum frequency in their daily meal compared to children age group between 6-11months. This study also supported by studies conducted in Ethiopia, India, and Seri Lanka $[9,11,12]$. This might be occurred due to the fact that for the infants during 6-11 months, mothers did not introduce semi solid and soft food; they are simply fed on animal or canned 
Table 5 A bivariate and multivariate logistic regression output showing factors associated with minimum meal frequency practice in 06 to 23 months children, Dangila, Northwest Ethiopia, 2014

\begin{tabular}{|c|c|c|c|c|}
\hline \multirow[t]{2}{*}{ Characteristics } & \multicolumn{3}{|c|}{ Minimum meal frequency } & \multirow[t]{2}{*}{ AOR $(95 \% \mathrm{Cl})$} \\
\hline & Inadequate & Adequate & COR $(95 \% \mathrm{Cl})$ & \\
\hline \multicolumn{5}{|l|}{ Mother's education } \\
\hline Cannot write and read & $214(54.60)$ & $178(45.40)$ & 1.00 & 1.00 \\
\hline Primary education (1-8) & $123(55.20)$ & $100(44.80)$ & $0.977(0.702,1.36)$ & $0.912(0.612,1.359)$ \\
\hline Secondary education (9 12) & $85(38.80)$ & $134(61.20)$ & $1.895(1.353,2.654)$ & $1.347(0.832,2.181)$ \\
\hline Higher education & $34(39.50)$ & $52(60.50)$ & $1.839(1.143,2.959)$ & $1.022(0.531,1.966)$ \\
\hline \multicolumn{5}{|l|}{ Mother's work } \\
\hline Currently not work & $358(51.50)$ & $337(48.50)$ & 1.00 & 1.00 \\
\hline Currently working & $98(43.60)$ & $127(56.40)$ & $1.377(1.017,1.863)$ & $1.180(0.837,1.664)$ \\
\hline \multicolumn{5}{|l|}{ Age of a child(months) } \\
\hline $06-11$ & $237(70.10)$ & $101(29.90)$ & 1.00 & 1.00 \\
\hline $12-17$ & $125(43.60)$ & $162(56.40)$ & $3.041(2.187,4.229)$ & $3.025(2.141,4.274)$ \\
\hline $18-23$ & $94(31.90)$ & $201(68.10)$ & $5.018(3.579,7.035)$ & $5.028(3.524,7.175)$ \\
\hline \multicolumn{5}{|l|}{ Birth Order of index child } \\
\hline First & $135(52.10)$ & $124(47.90)$ & 1.00 & 1.00 \\
\hline Second to fourth & $270(48.80)$ & $283(51.20)$ & $1.141(0.849,1.533)$ & $1.580(1.133,2.205)$ \\
\hline Above fourth & $51(47.20)$ & $57(52.80)$ & $1.217(0.776,1.908)$ & $1.778(1.068,2.958)$ \\
\hline \multicolumn{5}{|l|}{ Breast feeding status } \\
\hline No & $41(41.00)$ & $59(59.00)$ & 1.00 & 1.00 \\
\hline Yes & $415(50.60)$ & $405(49.40)$ & $0.671(0.445,1034)$ & $0.895(0.550,1.454)$ \\
\hline \multicolumn{5}{|l|}{ Decision making at household } \\
\hline Mothers not involved & $127(61.70)$ & 79 (38.30) & 1.00 & 1.00 \\
\hline Mothers involved & $329(46.10)$ & $385(53.90)$ & $1.881(1.370,2.583)$ & $1.512(1.053,2.170)$ \\
\hline \multicolumn{5}{|l|}{ Media exposure } \\
\hline Unsatisfactory & $335(59.10)$ & $232(40.90)$ & 1 & 1.00 \\
\hline Satisfactory & $121(34.30)$ & $232(65.70)$ & $2.769(2.100,3.65)$ & $2.620(1.901,3.611)$ \\
\hline \multicolumn{5}{|l|}{ Residence } \\
\hline Rural & $240(46.20)$ & $280(53.80)$ & 1.00 & 1.00 \\
\hline Urban & $216(54.00)$ & $184(46.00)$ & $1.37(1.054,1.779)$ & $1.243(0.849,1.821)$ \\
\hline \multicolumn{5}{|l|}{ Home gardening } \\
\hline No & $418(50.70)$ & $407(49.30)$ & 1.00 & 1.00 \\
\hline Yes & $38(40.00)$ & $57(60.00)$ & $0.050(1.000,2.374)$ & $1.412(0.878,2.273)$ \\
\hline \multicolumn{5}{|l|}{ Place of birth } \\
\hline Home & $240(46.20)$ & $280(53.80)$ & 1.00 & 1.00 \\
\hline Institution & $216(54.00)$ & $184(46.00)$ & $1.277(0.946,1.723)$ & $1.045(0.689,1.583)$ \\
\hline \multicolumn{5}{|l|}{ Time of post natal care visit } \\
\hline Missing & $158(53.60)$ & $137(46.40)$ & 1.00 & 1.00 \\
\hline Within $1-2$ days & $22(27.20)$ & $59(72.80)$ & $3.093(1.802,5.310)$ & $2.295(1.269,4.150)$ \\
\hline Within 3-6 days & $78(48.40)$ & $83(51.60)$ & $1.227(0.835,1.803)$ & $0.860(0.553,1.337)$ \\
\hline After 7 days & $198(51.70)$ & $185(48.30)$ & $1.078(0.795,1.461)$ & $0.848(0.598,1.189)$ \\
\hline
\end{tabular}

AOR Adjusted Odd Ratio, COR Crude Odd Ratio, Cl Confidence Interval 
milk along with breast milk. Unfortunately, however, the definition of minimum meal frequency, did not not consider breast milk while calculating minimum meal frequency for breast feed infants.

The study found that Children born in the second to fourth order [AOR 1.58; $95 \% \mathrm{CI}(1.13,2.21)$ ] and above fourth order [AOR 1.78; $95 \% \mathrm{CI}(1.07,2.96)]$ were more likely to met the minimum meal frequency as compared with children who were born first order. This difference could be due to mothers who give birth for first time may have less knowledge than those of multi parity mothers. And also as mother's parity increased mothers become experienced how to feed children frequently.

Involvement of mothers in household decision making found to be significantly associated with minimum meal frequency. Children from mothers involved in decision making in the house hold were 1.5 times[AOR 1.51; $95 \%$ CI (1.05-2.17)] more likely to provide the recommended meal frequency as compared to the children from the mothers not involved in decision making in the household. This study also in line with study conducted in India [11]. The possible explanation for this difference may be, most of the time the responsibility of child feeding is on the shoulders of mother even if the source is from husbands in Ethiopian context [20]. So participation of mothers with their household issues, they can access household resources easily and contribute that mothers can fed the children more frequently.

Children born from mothers who were exposed to media, i.e., watched television, listened to radio and read newspapers or magazines every day or at least once a week has more likely to meet minimum meal frequency [AOR 2.62; $95 \%$ CI (1.90-3.61)] than those children born from mothers who watched television, listened to radio and read newspapers or magazines less than once a week or not at all. This study is similar with other studies conducted in Ethiopia, Nepal, Seri Lanka and India [9, 11, 12, 14]. The reason behind for this could be currently there is a media promotion using radio and television that promote and show practice of IYCF. This may reflect broadly the power of mass media for improvement meal frequency practice.

Mothers who had attended PNC within 1-2 day after delivery [AOR 2.30; $95 \%$ CI (1.27-4.15)] were more likely to provide recommended meal frequency than mothers who had no PNC visit. Nutritional counseling for mothers about frequent feeding during PNC is important continuum and Mothers who have attended PNC visits may be more informed, have greater access to services and may be from a well off family, and thus more likely to be able to afford and provide of foods more frequently to their children.

The study is not free of recall bias and social desirability bias. It may not also accurately reflect childrens' past feeding experience since it considers only 24-hour feed.
This study does not take account of the quality and amount of food provided.

\section{Conclusion}

Infant and young children aged between 06-23 months receiving minimum dietary diversity score and minimum meal frequency is low compared with other countries.

Age of a child, birth order of index child and media exposure of a mother consistently associated both minimum dietary diversity and meal frequency practices. In addition, education level of a mother, residence and home gardening has significant association with minimum dietary diversity while mother's involvement in household decision making and postnatal visit have significant association with minimum meal frequency. Promoting women empowerment, home gardening and nutrition education is highly recommended to improve infant and young child feeding practice.

\section{Abbreviations \\ ANC: Antenatal Care; DHS: Demographic and Health Survey; EDHS: Ethiopian Demographic and Health Survey; IYCF: Infant and Young Child Feeding; MDD: Minimum Dietary Diversity; MDG: Millennium Development Goals; MMF: Minimum Meal Frequency; PNC: Postnatal Care; WHO: World Health Organization.}

\section{Competing interests}

None of the authors have any conflict of interest on the content of this manuscript.

\section{Authors' contributions}

$M B$ initiated the research, wrote the research proposal, conducted the research, did data entry and analysis and wrote the research and manuscript. AGW and MMW involved in the write up of the proposal, data analysis, interpretation and manuscript writing. All authors read and approved the final manuscript.

\section{Authors' information}

Not applicable.

\section{Acknowledgement}

Authors would like to thank the University of Gondar, Dangila Town Administration Office, Dangila Town Health Office and respective Kebele Administrations, study participants, data collectors, supervisors and Dangila Town health extension workers.

\section{Author details}

${ }^{1}$ Department of Public Health, Mizan-Tepi University, P.O. Box 260, Mizan-Aman, Ethiopia. '2Department of Reproductive Health, Institute of Public Health, University of Gondar, P.O. Box 196, Gondar, Ethiopia. ${ }^{3}$ Department of Human Nutrition, Institute of Public Health, University of Gondar, P.O. Box 196, Gondar, Ethiopia.

Received: 19 June 2015 Accepted: 23 September 2015

Published online: 03 October 2015

\section{References}

1. Federal Democratic Republic of Ethiopia Ministry of Health. Complimentary feeding practices for children aged 6 up to 24 months. Addiss Ababa, Ethiopia, 2012

2. World Health Organization. Guiding principles for feeding non-breastfed children 6-24 months of age. 2005.

3. Infant and Young Child Feeding Practices. Collecting and Using Data: A Step-by- Step Guide. Cooperative for Assistance and Relief Everywhere, Inc. (CARE). 2010. 
4. World Health Organization. Indicators for assessing infant and young child feeding practices: part 1: definitions: conclusions of a consensus meeting held 6-8 November 2007 in Washington DC, USA. 2008.

5. World Health Organization. Infant and young child feeding Model Chapter for textbooks for medical students and allied health professionals. Vol. II. Geneva Switzerland; 2009.

6. Victora CG, Adair L, Fall C, Hallal PC, Martorell R, Richter L, et al. Maternal and child undernutrition: consequences for adult health and human capital. Lancet. 2008;371(9609):340-57.

7. Black RE, Allen LH, Bhutta ZA, Caulfield LE, de Onis M, Ezzati M, et al. Maternal and child undernutrition: global and regional exposures and health consequences. Lancet. 2008;371(9608):243-60

8. Central Stastical Agency. Ethiopia Demographic and Health Survey 2011. Addis Ababa, Ethiopia, 2013.

9. Mesele M, Aemro M, Atenafu A, Birhanu Z. Dietary diversity and meal frequency practices among infant and young children aged 6-23 months in Ethiopia: a secondary analysis of Ethiopian Demographic and Health Survey 2011. J Nutr Metab. 2013;2013:782931.

10. World Health Organization. Indicators for assessing infant and young child feeding practices part 3: country profiles. 2010.

11. Patel A, Pusdekar Y, Badhoniya N, Borkar J, Agho KE, Dibley MJ. Determinants of inappropriate complementary feeding practices in young children in India: secondary analysis of National Family Health Survey 2005-2006. Matern Child Nutr. 2012;8(s1):28-44.

12. Senarath U, Godakandage SS, Jayawickrama H, Siriwardena I, Dibley MJ. Determinants of inappropriate complementary feeding practices in young children in Sri Lanka: secondary data analysis of demographic and health survey 2006-2007. Matern Child Nutr. 2012;8(s1):60-77.

13. Kabir I, Khanam M, Agho KE, Mihrshahi S, Dibley MJ, Roy SK. Determinants of inappropriate complementary feeding practices in infant and young children in Bangladesh: secondary data analysis of Demographic Health Survey 2007. Matern Child Nutr. 2012;8(s1):11-27.

14. Joshi N, Agho KE, Dibley MJ, Senarath U, Tiwari K. Determinants of inappropriate complementary feeding practices in young children in Nepal: secondary data analysis of Demographic and Health Survey 2006. Matern Child Nutr. 2011:8 Suppl 1:45-59.

15. Khanal V, Sauer K, Zhao Y. Determinants of complementary feeding practices among Nepalese children aged 6-23 months: findings from demographic and health survey 2011. BMC Pediatr. 2013:13(1):1-13.

16. Sapkota S, Shrestha S. Complimentary feeding practices among the care takers of the young children at Kathmandu. J Chitwan Med Coll. 2014;3(6):25-9.

17. Khan AM, Kayina P, Agrawal P, Gupta A, Kannan AT. A study on infant and young child feeding practices among mothers attending an urban health center in East Delhi. Indian J Public Health. 2012;56(4):301.

18. Senarath U, Dibley MJ. Complementary feeding practices in South Asia: analyses of recent national survey data by the South Asia Infant Feeding Research Network. Matern Child Nutr. 2012:8(s1):5-10.

19. Senarath U, Agho KE, Akram DE, Godakandage SS, Hazir T, Jayawickrama H, et al. Comparisons of complementary feeding indicators and associated factors in children aged 6-23 months across five South Asian countries. Matern Child Nutr. 2012:8:89-106.

20. Academy for Educational Development (AED), Alive \& Thrive Ethiopia Country Office, Initial Insight Mining and Pretest Research for Alive \& Thrive Ethiopia. Howard Delafield International, LLP (HDI) Marketing and Communications, August 2011

21. Ng CS, Dibley MJ, Agho KE. Complementary feeding indicators and determinants of poor feeding practices in Indonesia: a secondary analysis of 2007 Demographic and Health Survey data. Public Health Nutr. 2012;15(5):827-39.

22. Tessema M, Belachew T, Ersino G. Feeding patterns and stunting during early childhood in rural communities of Sidama, South Ethiopia. Pan Afr Med J. 2013;14:75

\section{Submit your next manuscript to BioMed Central and take full advantage of:}

- Convenient online submission

- Thorough peer review

- No space constraints or color figure charges

- Immediate publication on acceptance

- Inclusion in PubMed, CAS, Scopus and Google Scholar

- Research which is freely available for redistribution 